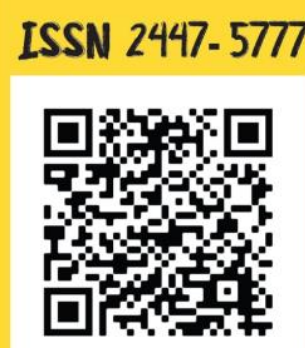

$\varepsilon$

$\mathbf{M}$

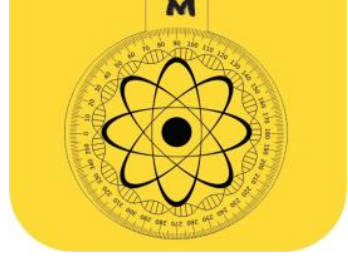

MULTIDISCIPLINARIDADE

Jan. | Jun. 2021, Volume 7, Número 1, p. 91-110.

\title{
Mulheres, flores e suas prisões: reflexões sobre botânica, gênero e ciência com alunas privadas de liberdade
}

\author{
Women, flower and their prisons: reflections about botany, gender, science and \\ the social condition of women with female students inmates
}

\author{
Iamni Torres Jager ${ }^{1}$ - https://orcid.org/0000-0001-9741-0126 \\ Andreia Guerra de Moraes ${ }^{2}$ - https://orcid.org/0000-0002-6397-3817
}

\begin{abstract}
${ }^{1}$ Mestre em Ciência, Tecnologia e Educação pelo Centro Federal de Educação Tecnológica Celso Suckow da Fonseca (CEFET-RJ). Doutoranda no Programa de Pós-graduação em Ciência, Tecnologia e Educação do Centro Federal de Educação Tecnológica Celso Suckow da Fonseca (CEFET-RJ) e docente da Educação Básica na Secretaria Estadual de Educação do Rio de Janeiro (SEEDUC-RJ), Rio de Janeiro, Rio de Janeiro, Brasil. E-mail: iamni.jager@gmail.com

${ }^{2}$ Doutora em Engenharia de Produção pela Universidade Federal do Rio de Janeiro (UFRJ). Professora no Programa de Pós-graduação em Ciência, Tecnologia e Educação do Centro Federal de Educação Tecnológica Celso Suckow da Fonseca (CEFET-RJ), Rio de Janeiro, Rio de Janeiro, Brasil. E-mail: andreia.guerra96@gmail.com
\end{abstract}

\begin{abstract}
Resumo
Este artigo apresenta uma pesquisa realizada em aulas de ciências desenvolvidas com base na vertente da História Cultural da Ciência com foco nas práticas botânicas durante os séculos XVIII e XIX. A investigação ocorreu junto ao grupo de pesquisa NIEHCC e com alunas privadas de liberdade, quando do estudo de temas do conteúdo de Biologia na Educação de Jovens e Adultos (ecologia, nomenclatura científica, botânica). O recorte histórico suscitou discussões sobre as relações entre gênero e ciência, a partir da discussão da participação feminina na Botânica no recorte histórico selecionado. A pesquisa histórica indicou que as práticas científicas em que as mulheres se envolveram, em geral, eram restritas ao espaço privado e derivaram de um interesse do contato das mulheres com a ciência. O método etnográfico foi escolhido para análise das intervenções em sala de aula. As alunas trouxeram para as aulas temáticas como homossexualidade, machismo, maternidade na adolescência, papel da mulher, diferenças entre os gêneros, opressões, violência masculina no seio familiar e barreiras no acesso da mulher à escola e ao trabalho, apontando que a abordagem da História Cultural da Ciência possibilitou conectar discussões sobre práticas científicas com o contexto das alunas.
\end{abstract}

Palavras-chave: Ensino de Ciências. Gênero e Ciência. História Cultural da Ciência. Educação Prisional.

Como citar: JAGER, I. T.; MORAES, A. G. Mulheres, flores e suas prisões: reflexões sobre botânica, gênero e ciência com alunas privadas de liberdade. Ensino \& Multidisciplinaridade, v. 7, n. 1, p. 91-110, 2021. 


\begin{abstract}
The paper reports the results of a study carried out in science classes from the Cultural History of Science approach, focusing on Botanical practices during the 18th and 19th centuries. The investigation was carried out with the NIEHCC research group and with students deprived of liberty when studying topics of Biology in Youth and Adult Education's mandatory curriculum (ecology, the scientific terminology, botany). The historical episode aimed to raise discussions about the relations between gender and science with the students, as many women participated in Botany in the selected historical section. The historical research indicated that the scientific practices in which women were involved, in general, were restricted to the private space and derived from an interest in women's contact with science. The ethnographic method was chosen to give voice to the speech of the participating students. Themes as homosexuality, sexism, adolescent motherhood, women's role, gender differences, oppression, male violence within the family, and barriers to women's access to school and work emerged in class, which indicates that the historical discussions were related to the students' context.
\end{abstract}

Keywords: Science Education. Gender and Science. Cultural History of Science. Prison Education.

\title{
Introdução
}

O papel da escola na formação de sujeitos críticos e atentos às questões de gênero, junto a uma educação em ciências que propague o conhecimento científico como temporalmente e espacialmente situado, é crucial para a construção de uma nova ciência, que seja mais plural, crítica e democrática (MUZZIN, 2005; OLIVEIRA; QUEIROZ, 2016). No Brasil, inclusive, diversos documentos legais pautam as questões de direitos humanos, incluindo discussões sobre o papel social da mulher, a erradicação da discriminação racial e de gênero, assim como a igualdade entre os gêneros (BRASIL, 1996; 2004; 2006; 2007; 2010; 2012a; 2012b; 2014).

Ao olharmos para a realidade escolar a qual estamos inseridas, falar do papel da mulher na ciência torna-se ainda mais urgente. A escola em questão é uma instituição pública e situase no interior de uma penitenciária feminina da cidade do Rio de Janeiro. Para entender esse contexto escolar, precisamos relacioná-lo à crise institucional e econômica vivida hoje no Brasil que, conjugada a políticas de segurança pública que criminalizam o uso e venda de entorpecentes, promoveu um encarceramento em massa, principalmente de mulheres (BRASIL, 2017). Dados e pesquisas sobre gênero mostram que a participação feminina no tráfico de drogas tem crescido rapidamente nas últimas décadas e, dentre os motivos apontados para esse crescimento, constam as condições ligadas ao gênero. Como exemplo, destacamos a insistência dos companheiros para as práticas ilícitas ou a necessidade das mulheres de sustentarem sozinhas a casa e os filhos (BARCINSKI, 2012; MINZON; DANNER; BARRETO, 2010; MOURA; FROTA, 2006). Nesse sentido, explicitar as tensões de gênero presentes na sociedade, do passado e do presente, faz-se necessário na escola prisional para que, cientes da sua história e da sua realidade, essas alunas possam almejar um caminho para a retomada de suas vidas e a transformação da sua realidade.

Com base nessas considerações, realizamos uma pesquisa com alunas dessa escola em aulas de ciência, desenvolvida de forma coletiva junto ao Núcleo de Investigação em Ensino, História da Ciência e Cultura (NIEHCC), grupo de pesquisa do qual fazemos parte. Porém, apenas uma de nós, aqui colocada como professora-pesquisadora, foi quem efetivamente esteve inserida no espaço escolar e conduziu a pesquisa em sala de aula. Durante os quatro anos anteriores ao início da investigação, a professora-pesquisadora atou como docente nessa escola e observou que, na maioria dos casos, suas alunas encontravam-se em privação de liberdade por cooperação ou ocultação de crimes cometidos pelos seus companheiros ou por verem no varejo de drogas a possibilidade de sustentar a casa e os filhos (JAGER, 2021). Além disso, era frequente relatos de violência física e emocional cometidas por homens (pais, irmãos, filhos, companheiros) a essas mulheres. Portanto, enquanto pesquisadora, ela entendeu que trazer para a sala de aula discussões acerca da participação feminina na construção científica seria uma 
forma de discutir o conteúdo formal da disciplina, bem como o papel da mulher na sociedade, além de possibilitar reflexões sobre a própria condição momentânea de encarceramento ao qual as alunas estavam submetidas. O currículo mandatório da escola e trabalhos anteriores do grupo de pesquisa (CAMEL; MOURA; GUERRA, 2019; JARDIM; GUERRA, 2017) indicaram como caminho o estudo histórico das práticas científicas, mais especificamente das práticas botânicas durante os séculos XVIII e XIX à luz da vertente historiográfica da História Cultural da Ciência (HCC).

A escolha pela História Cultural da Ciência como método historiográfico nos permitiu produzir uma narrativa que enfocasse as assimetrias de poder existentes na construção do conhecimento científico, bem como os agentes beneficiados ou vulnerabilizados nesse processo. Isso porque com base na $\mathrm{HCC}$ entendemos que "todo fato científico, toda teoria ou toda prática relacionada com o conhecimento da natureza é um fato profundamente cultural" (PIMENTEL, 2010, p. 418). Logo, os produtos, regras e modos de produção da ciência não estão isolados, e sim inseridos em um contexto amplo, relacionado e interligado a uma grande rede política, econômica, social, institucional, e, portanto, cultural. Nessa proposta historiográfica, as práticas científicas mostram-se como elementos privilegiados de análise histórica. Isto porque elas nos permitem observar todo um conjunto complexo que envolve as ações dos cientistas e de outros agentes sociais direta ou indiretamente envolvidos nestas ações, as escolhas dos cientistas por determinados métodos e os seus relacionamentos com instituições e grupos sociais enfim, toda uma rede de relações estabelecidas na prática cotidiana do cientista (GAVROGLU, 2007; MOURA; GUERRA, 2016). Este olhar mais atento sobre as práticas científicas para o estudo do desenvolvimento da Botânica nos séculos XVIII e XIX nos permitiu traçar trajetórias que perpassam por indivíduos, instituições e relações de poder, tanto econômico, como é a questão dos financiamentos de pesquisa, quanto social, no caso de grupos ou pessoas mais influentes no contexto científico estudado (GAVROGLU, 2007). Os instrumentos científicos, assim como sua história de produção, utilização e legitimação perante as sociedades científicas, também, foram instrumentos de pesquisa historiográfica (GAVROGLU, 2007; PIMENTEL, 2007, 2010). Da mesma forma, as diferentes imagens produzidas no contexto histórico estudado foram fontes primárias fundamentais para a pesquisa histórica ao nos permitir perceber a interação entre a produção artística e a produção científica do momento histórico, tanto através da imagem retratada, como através da forma como foi ela produzida (PIMENTEL, 2010).

Além do fato do tema botânica ser parte do currículo mandatório, consideramos pesquisas históricas que apontam para a importância do trabalho feminino na construção da Botânica (GEORGE, 2006; 2014; GIANQUITTO, 2007) para selecionarmos esse tema. Portanto, em um primeiro momento, foi realizada uma pesquisa historiográfica em fontes primárias e secundárias, relacionadas ao estabelecimento da Botânica nos séculos XVIII e XIX, a partir da vertente historiográfica da HCC, com foco na participação feminina nesse campo da ciência, e, assim, construiu-se um olhar interseccional para a presença feminina, especificando a localização geográfica dessas mulheres, sua classe social, nível de escolaridade, cor, idioma e cultura (JAGER, 2018).

A segunda parte da pesquisa consistiu em atividades desenvolvidas durante as aulas de Biologia pela professora-pesquisadora e envolveu 4 mulheres adultas privadas de liberdade, alunas do Ensino Médio da Nova Educação de Jovens e Adultos de uma escola prisional carioca. A partir da pesquisa historiográfica construída, foram trabalhados conteúdos do currículo mínimo de Biologia, tendo como forma de análise e coleta de dados o método etnográfico (JAGER, 2018). O método etnográfico, assim como defende Mattos (2011), mostrou-se crucial para dar voz às discussões trazidas em sala de aula, já que por questões de 
segurança impostas pelo sistema penitenciário do Estado nenhuma atividade pôde ser filmada ou fotografada, assim como nenhuma aluna participante foi identificada.

Com isso buscamos construir subsídios capazes de gerar respostas à seguinte pergunta: que elementos em torno ao papel da mulher podem ser elencados em aulas de ciências, por alunas privadas de liberdade, a partir do estudo da Botânica à luz da vertente historiográfica da HCC?

Para responder a nossa pergunta de pesquisa, iniciamos o artigo com uma breve apresentação dos resultados da pesquisa histórica. Em seguida, apresentamos uma narrativa sobre a intervenção em sala de aula com base nos registros e análises etnográficas. Finalizamos o artigo com algumas considerações finais.

\section{A botânica como ramo condutor da educação feminina na Época das Luzes}

A atividade botânica passou por uma grande mudança durante os séculos XVIII e XIX na Europa em geral, incluindo também suas colônias, alterando a percepção utilitária dessa ciência (BLEICHMAR, 2011; GRONIM, 2007; SIGRIST; WIDMER, 2011). Antes voltada para a função farmacêutica, a botânica começou a adquirir um forte caráter econômico no início do século XVIII, já que os colonizadores tinham grande interesse em cultivar em suas terras as novas espécies encontradas nas colônias e ampliar sua rede comercial e margem de lucro (BLEICHMAR, 2011). Esta mudança no perfil da atividade Botânica exigia de seus praticantes o conhecimento de novas práticas, dentre elas o uso de instrumentos como agulhas e estiletes na dissecção de plantas, de lupa e microscópios para aumento das estruturas florais, coleta e prensagem de plantas, anotações sobre as observações de campo, a troca de informações com outros indivíduos, classificação de plantas e desenhos botânicos (BLEICHMAR, 2011; GEORGE, 2006; GRONIM, 2007; PAGE; SMITH, 2011; SHEFFIELD, 2006; SIGRIST; WIDMER, 2011).

Segundo a análise de Sigrist e Widmer (2011), havia milhares de atores no empreendimento botânico com diferentes graus de prestígio, formação e atuação, e cuja posição social variava de acordo com a prática exercida. Entretanto, apenas algumas centenas de homens brancos e com poder econômico podem ser vistos como profissionalizados nessa rede. Além disso, cabia a eles as atividades de gabinete, como o recebimento de correspondências, validação e publicação das novas espécies (BLEICHMAR, 2011; SIGRIST; WIDMER, 2011). Em geral, estes homens eram mais velhos, tinham influência e participação em sociedades ou academias científicas de prestígio da época, além de exercerem o papel de mestres, transmitindo seus conhecimentos a um ou mais discípulos (SIGRIST; WIDMER, 2011). Nesse contexto, muitos botânicos renomados, como John Lindley (1799-1865), defendiam que a produção científica na botânica deveria ser uma tarefa exclusivamente masculina (SHEFFIELD, 2006).

Aos homens mais jovens era incentivada a participação em expedições às colônias europeias que tinham como objetivo coletar, identificar e descrever plantas nunca antes conhecidas pelos europeus. Essa participação era vista como uma oportunidade de inserção desses jovens ao meio científico (BLEICHMAR, 2011; BURKE, 2011). Na Espanha, por exemplo, homens cirurgiões eram recrutados para trabalhar com a Botânica durante as expedições, por conta de seu olhar treinado e aguçado. Porém, para ingressar nas expedições eles faziam cursos, oferecidos pelo próprio Jardim Botânico de Madri (BLEICHMAR, 2011). Livros como Instruccion sobre el modo mas seguro y económico de transportar plantas vivas por mar y terra a los paises más distantes, de Casimiro Gómez Ortega, membro da Sociedade Botânica de Florença e da Real Academia Médica de Madri, serviram como manuais de conduta profissional para esses jovens viajantes, a fim de diminuir a perda de espécimes coletados (ORTEGA, 1779). A coleta de plantas em si era vista como uma atividade inferior, sendo 
comum sua realização por pessoas do campo e nativos das colônias (BLEICHMAR, 2011). Estes faziam a coleta, anotações e prensagem e algumas das vezes até a classificação de plantas, além de remeterem suas observações a botânicos renomados (BLEICHMAR, 2011; GRONIM, 2007; SIGRIST; WIDMER, 2011). Também muitos homens e mulheres das classes médias e da aristocracia europeia praticavam a Botânica como forma de entretenimento e se correspondiam com botânicos profissionais, enviando anotações e espécimes.

Por conta de muitas das práticas botânicas poderem ser realizadas em ambientes domésticos, inclusive nos jardins das próprias residências, ela se tornou rapidamente popular entre as mulheres europeias do século XVIII (SHTEIR, 2016). A união dessas características fez com que a botânica tivesse, além de sua crescente importância econômica e científica, um papel crucial na concretização do desejo iluminista para a educação feminina. Isso porque, ao exercê-la, a mulher poderia ter contato com o pensamento científico e estar mais apta a educar seus filhos para serem cidadãos iluministas, além de poder sustentar uma conversa interessante durante reuniões sociais. Isso permitia que elas pudessem exercer as atividades delegadas a elas socialmente, como cuidar dos filhos e da casa, e ao mesmo tempo estudarem em um ambiente reservado, com plantas nativas encontradas ali mesmo (GEORGE, 2006, 2014; PAGE; SMITH, 2011; SHEFFIELD, 2006; SHTEIR, 2016).

Importante aqui destacar que a botânica desejável às mulheres apresentava restrições quanto às práticas. A mulher, assim como defendido por filósofos iluministas, como Rousseau e Kant (GASPAR, 2009), era vista como um ser próximo do mundo natural logo, coletar plantas e observá-las era uma tarefa compatível a este gênero biológico. Já práticas consideradas mais intelectuais, como viagens exploratórias, publicações de livros e discussões sobre a correta classificação de gêneros botânicos, por exemplo, não eram adequadas às mulheres, tanto por questões relacionadas à moral e ao papel social da mulher, quanto por uma incompatibilidade com a própria biologia feminina, segundo essa visão filosófica. Apesar de encontrarmos filósofos, como Condorcet e Hume, que divergiam desse olhar determinista e inferior quanto à natureza da mulher, acabou por caber à maioria daquelas mulheres um tipo específico de ciência, que pode ser percebido ao longo do século XVIII através da quantidade de publicações com temas botânicos dirigidos especificamente às mulheres (GEORGE, 2006, 2014; GIANQUITTO, 2007; SHTEIR, 1990).

Nas seções seguintes apresentamos a metodologia e os resultados das intervenções pedagógicas, retomando algumas questões discutidas.

\section{Caminhos da prática}

As intervenções pedagógicas, organizadas com base no estudo histórico, foram feitas ao longo de dois meses, durante as aulas de Biologia, totalizando cerca de 22 horas de intervenção. Para a composição das aulas, utilizamos imagens produzidas durante o recorte histórico da pesquisa e também slides produzidos pela professora-pesquisadora. Essas imagens mostram pinturas artísticas do cotidiano de indivíduos da aristocracia europeia, muitos deles envolvidos no empreendimento científico, bem como imagens contidas em livros de botânica da época. A escolha de trabalhar com imagens produzidas no contexto histórico nas aulas deve-se ao fato de concordarmos com Loizos (2015) que a utilização de imagens em sala de aula possibilita aos estudantes a leitura tanto das presenças como das ausências de um registro visual. Isso significa que, ao trazermos imagens produzidas durante o contexto histórico abordado, podemos discutir a importância ou não de determinados indivíduos e grupos sociais, bem como práticas cotidianas da sociedade da época e seus atores.

\section{Refletir coletivamente e libertar vozes}

Ensino \& Multidisciplinaridade, São Luís (MA), v. 7, n. 1, p. 91-110, 2021. 
Houve a preocupação em atender ao conteúdo formal de biologia, em concordância com o currículo mínimo para o Ensino Médio e o programa da Nova Educação de Jovens e Adultos adotado pela Secretaria Estadual de Educação do Rio de Janeiro, abordando as temáticas de ecologia geral, biodiversidade, biologia e reprodução vegetal, nomenclatura, fundamentos e metodologia científica. Porém, vale ressaltar que a abordagem histórica não visou aumentar a aprendizagem do conteúdo da disciplina, mas sim trazer à tona discussões e correlações entre as ciências e seu contexto cultural.

Coerente com a metodologia etnográfica, os dados foram recolhidos principalmente através do diário de campo, a fim de possibilitar: um retrato dos sujeitos e do ambiente escolar; reconstruções de diálogos; o relato de acontecimentos particulares; e a descrição de atividades e dos comportamentos observados a partir de um relato descritivo, mas, também, reflexivo dos fenômenos (OLIVEIRA, 2013). Segundo Oliveira (2013), na etnografia o diário de campo é um instrumento que permite um afastamento do campo, possibilitando ao pesquisador, quando transformada a vivência em texto, fazer uma análise do desenvolvimento da pesquisa e uma autoanálise da sua participação nela. Cabe aqui destacar que, apesar de o diário de campo se propor a ser uma descrição densa das atividades presenciadas pelo pesquisador, ele não necessita que os sujeitos envolvidos no processo sejam identificados de forma individual e pessoal. Portanto, este trabalho não identificou as alunas participantes, bem como as intervenções pedagógicas não foram gravadas ou fotografadas.

Os relatos presentes no diário de campo foram escritos manualmente e imediatamente após a finalização de cada intervenção pedagógica pela professora-pesquisadora. Posteriormente, eles eram transcritos para o formato digital, o que fazia com que muitos dos relatos fossem revisitados e complementados. Portanto, o diário de campo apresentado neste trabalho é fruto de um processo reflexivo, que envolveu idas e vindas ao texto, acrescentando percepções sobre as situações vivenciadas em campo. Além do diário de campo, foram recolhidas produções textuais e desenhos confeccionados pelas alunas durante as intervenções pedagógicas. Ao longo do desenvolvimento da pesquisa, os relatos do diário eram apresentados ao grupo de pesquisa, de forma que a análise do processo ocorreu a partir do entrelaçamento de vozes dos integrantes do grupo.

$\mathrm{Na}$ próxima seção, dialogamos com as observações trazidas pelo diário de campo etnográfico, como forma de apresentar as discussões e reflexões ocorridas em sala de aula. Como forma de sistematizar melhor os resultados elencamos temáticas que foram construídas a partir dos resultados obtidos em cada um dos dias da intervenção em sala de aula e dos temas de ciências trabalhados no respectivo dia. Dessa forma, a discussão, a partir das temáticas selecionadas, visou responder à pergunta central da pesquisa.

\title{
Machismo, violência, sonhos e negação de direitos: o perfil das alunas pesquisadas.
}

\begin{abstract}
É muito difícil ser criativa estando tanto tempo presa. (...) aqui na escola é o lugar que eu me sinto mais livre (...) eu tive que abandonar a escola porque não tinha quem ficasse com a minha bebê e ele era muito ciumento (...). Eu queria ser veterinária porque amo bichos (...) eu espero terminar a escola e dar isso de exemplo para os meus filhos. (Relatos retirados do diário de campo etnográfico).
\end{abstract}

A violência física é uma constante na história dessas mulheres, e foi praticada pelo companheiro no caso de duas delas, e por familiares no caso de outra. O machismo, também, se mostrou presente de diversas formas nas falas dessas alunas, seja por conta das agressões físicas sofridas ou através da intimidação, limitando a liberdade individual dessas mulheres. Algumas delas apresentam personalidade instável e depressiva e, inclusive, declararam episódios de automutilação. 
Apenas uma das alunas que participou da pesquisa não era mãe e através dos relatos percebemos que a responsabilidade para com os filhos, de forma geral, é delas, e este fato é inclusive um empecilho para que elas continuassem os estudos após a gravidez. Ao serem encarceradas, elas precisaram delegar o cuidado com os filhos a terceiros, geralmente outras mulheres da família, o que causa a elas uma sensação de culpa e angústia. Apesar de terem em comum a negação de direitos enquanto mulheres, percebemos que elas tentaram de alguma forma, ao longo de suas trajetórias, romperem com estes obstáculos e explicitam que os filhos são a maior motivação para a mudança de vida após saírem da prisão.

Apesar da situação atual de encarceramento, todas elas relataram terem sonhado e planejado um presente diferente que, por motivos diversos, não puderam ser concretizados. Nesse sentido, elas explicitaram que a escola se mostrou um caminho importante na socialização delas, pois possibilita tanto uma redução de pena, através da remição pelo estudo, quanto garante uma oportunidade melhor de trabalho quando forem libertas. Além dessas motivações, elas relataram também a liberdade e a diversidade de ideias proporcionada durante $\mathrm{o}$ ato de estudar e o acolhimento dos professores como fatores importantes para a permanência na escola.

\section{Quem praticava ciência durante os séculos XVIII e XIX? Onde? Como?}

As mulheres fizeram ciência, mas os homens não reconheciam o trabalho delas (...) Só sendo rica para poder fazer isso (...) será que o uso medicinal da Aroeira foi catalogado na Enciclopédia? (...), mas nesse lugar só tem homem! (Relatos retirados do diário de campo etnográfico).

Durantes as primeiras intervenções pedagógicas, foram abordadas de forma mais enfática os locais e indivíduos produtores de ciência, assim como sua forma de comunicação e atuação. Isso foi discutido através de slides e falas da professora-pesquisadora, além da utilização de pinturas da época para discutir o que acontecia naquele contexto (Figuras 1, 2 e $3)$.

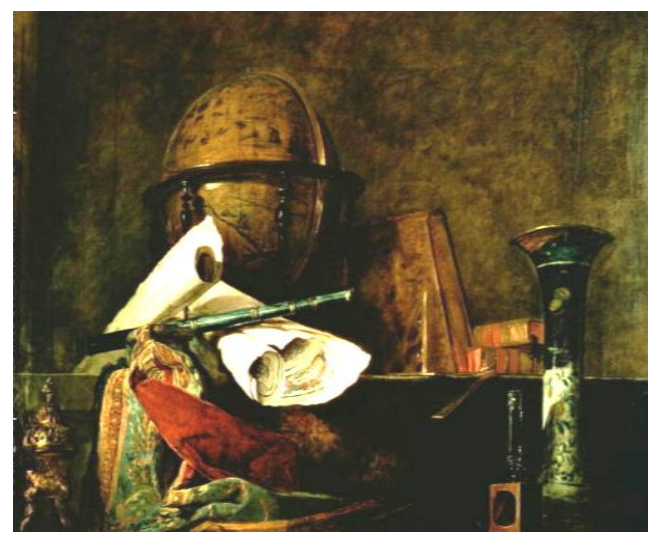

Figura 1 - Pintura Allegory of Science de Jean-Baptiste-Simeon Chardin, em 1765. Nesta imagem é possível observar a presença de diversos instrumentos científicos, como mapas, luneta, globo terrestre e livros, dividindo espaço com outros objetos pertencentes ao âmbito do lar, como vasos decorativos e uma manta.

Fonte: Chardin (1765) 


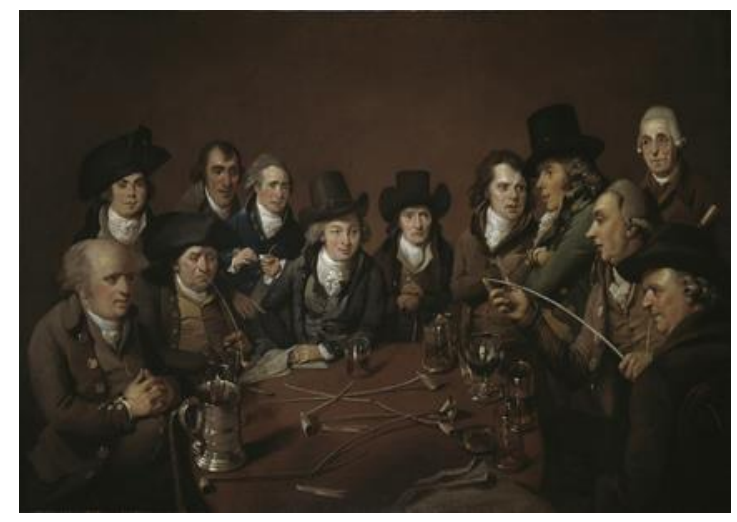

Figura 2 - Pintura John Freeth and his Circle de Johannes Eckstein (1736-1817), de 1792. John Freeth (1731-1808) era republicano, poeta e dirigia uma casa de café em Bell Street, Birmingham, onde ocorreu esta reunião do Clube Jacobino.

Fonte: Eckstein (1792)

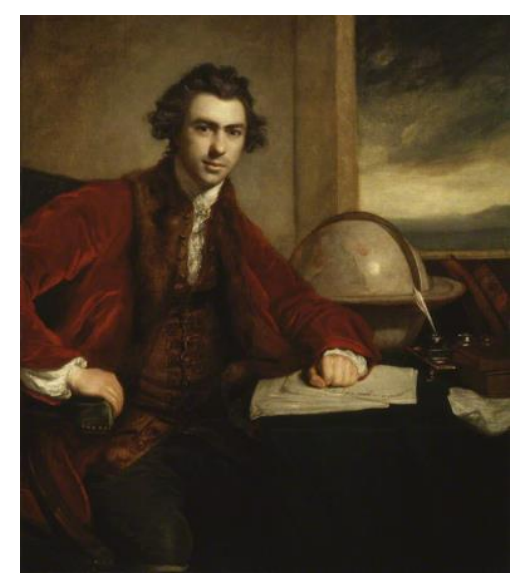

Figura 3 - Pintura retratando Joseph Banks (1743-1820), de Joshua Reynolds (1723-1792), em 1773. Banks realizou expedições à terras tropicais e alcançou fama como naturalista, tendo ocupado o cargo de presidente da Royal Society por mais de 41 anos.

Fonte: Reynolds (1773).

Durante essas discussões, pudemos perceber que as alunas caracterizaram a produção científica da época como masculina, europeia, produzida por indivíduos brancos, na maioria das vezes idosos, apesar de reconhecerem que havia alguns mais jovens. Através da observação das pinturas, elas realçaram a condição social e econômica privilegiada desses atores sociais, destacando a arquitetura do local retratado e as vestimentas das pessoas; muitas das vezes, comparando-as com suas condições pessoais enquanto mulheres negras e pobres.

Ao colocar a Europa como centro da produção científica foi possível trazer à tona discussões sobre a presença de atores não europeus na construção da ciência e as dificuldades para a inserção desses atores nessa produção. Nesse momento, discutiu-se a dificuldade do estrangeiro para com o idioma usado na comunicação entre os cientistas, o financiamento das pesquisas e as relações de poder naquele espaço. A situação da Enciclopédia, por exemplo, como conhecimento universalmente aceito, possibilitou visibilizar populações não-europeias (latinos, negros e indígenas) como atores deste processo, já que muito do conteúdo científico retratado em suas páginas havia sido trazido pelo contato com estes grupos sociais. Além disso 
foi colocada a cultura como componente essencial para o entendimento de todo o processo da construção científica e suas escolhas e ênfases em um ou outro conhecimento.

A relação entre ciência e religião também foi trabalhada a partir do viés cultural, mas não gerou muita discussão por parte das alunas. Em suas falas elas retrataram a ciência como uma forma de obter status e ostentar poder.

Durante a discussão das pinturas que retratavam os vários espaços de discussão científica, como casas de café e cerveja e sociedades científicas (Figura 2) foi levantada pelas alunas a ausência feminina nesses espaços produtores de ciência que, segundo elas, era reflexo da visão masculina sobre o papel e natureza da mulher. Foram destacadas também as práticas científicas "amadoras" e "profissionais", o contexto de formação profissional da época e os hábitos cotidianos de lazer. Ao frisar que as práticas científicas eram exercidas por homens e mulheres, porém com hierarquias de prestígio distintas, foram mostradas ilustrações científicas produzidas por mulheres, o que fez uma aluna pontuar a questão do treinamento adequado para a realização de tal função (Figuras 4 e 5).

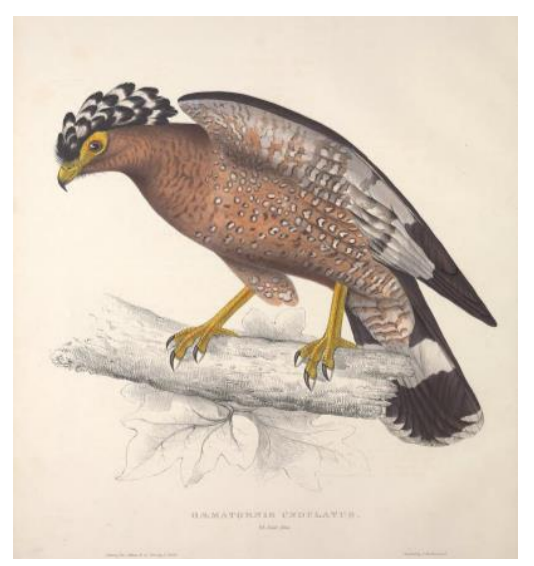

Figura 4 - Ilustração feita por Elisabeth Gould presente no livro de John Gould, A century of birds from the Himalaya Mountain, de 1831.

Fonte: Gould (1831)

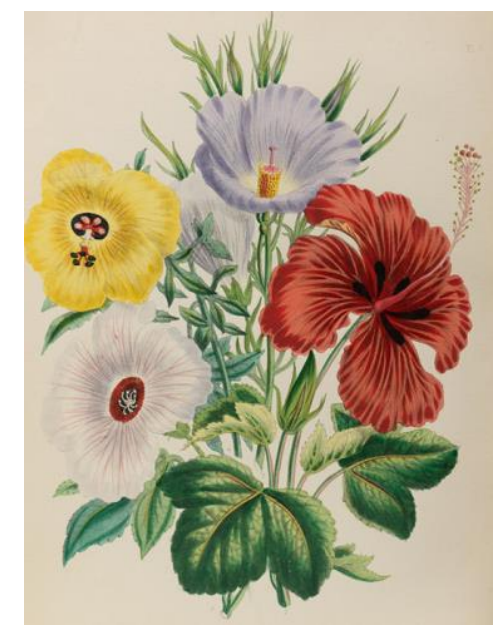

Figura 5 - Ilustração botânica presente no livro Ladies Flower-Garden of Ornamental Greenhouse Plants, de Jane Wells Loudon, de 1841.

Fonte: Loudon (1841). 
Novamente, foi abordada a forma de comunicação entre os indivíduos envolvidos naquela produção científica, desta vez enfatizando tanto as características de gênero e classe socioeconômica, quanto a localização geográfica como fatores determinantes do sucesso no empreendimento científico. As alunas concordaram que apesar das dificuldades e desigualdades existentes neste meio, as mulheres brancas europeias tinham algum tipo de voz e protagonismo. Foi colocado que, de forma geral, as mulheres que produziam conhecimento científico tinham uma situação que permitia isso, como o fato de serem esposas de homens envolvidos na ciência, de terem tido uma formação em ciência no âmbito doméstico, e que esta atuação se dava no âmbito privado do lar.

\section{O ser mulher: visão das alunas frente as posições filosóficas do papel da mulher na sociedade iluminista dos séculos XVIII e XIX.}

Antes era mais difícil, mas agora as mulheres podem fazer muitas coisas (...) nós mulheres somos diferentes dos homens, mas temos nossas habilidades, somos mais guerreiras (...) as mulheres podem cuidar da casa e dos filhos, mas também podem trabalhar. (Relatos retirados do diário de campo etnográfico)

As alunas participantes esboçaram reações e opiniões frente às visões filosóficas sobre a natureza da mulher explicitados pelos filósofos Rousseau, Kant, Hume e Condorcet (GASPAR, 2009). A leitura de textos dos próprios filósofos, unidos a fatos biográficos sobre suas vidas pessoais, gerou comentários por parte das alunas acerca dessas produções filosóficas.

$\mathrm{O}$ destaque de algumas mulheres que mantiveram relação com o filósofo Condorcet e seu parentesco com outras mulheres importantes à época possibilitou a discussão das relações existentes nesse meio, explicitando uma rede ampla de contatos entre esses atores sociais. Isso fez com que as alunas se vissem como indivíduos possivelmente excluídos daquele espaço, já que pertencem a um grupo social distinto daquele.

Durante falas espontâneas em sala de aula, surgiram opiniões que defendiam que mulheres e homens deveriam ser iguais em direitos e que ambos têm as mesmas capacidades cognitivas. Porém, uma aluna destacou que a capacidade cognitiva variava de acordo com o gênero e outra aluna rebateu essa consideração, afirmando que essas capacidades seriam determinadas pelas oportunidades dadas a homens e mulheres.

Nas produções textuais das alunas, houve novamente discordância das visões a respeito da natureza feminina propostas por Kant e Rousseau. Elas citaram que esses filósofos, ao contrário delas, acreditavam e propagavam que a mulher era inferior ao homem e por conta disso não estaria apta a realizar atividades de caráter intelectual. Além disso, elas ligaram diretamente essa forma de pensamento filosófico ao termo machismo, e uma das alunas explicitou em seu texto que tanto homens quanto mulheres podem ser machistas. Segundo os textos, o machismo atrapalharia a igualdade de direitos para os gêneros, tanto no passado como atualmente.

Nas produções textuais as alunas explicitaram, também, que atualmente, diferentemente do passado, homens e mulheres podem exercer as mesmas funções. Nos textos escritos pelas alunas, a partir de uma das atividades propostas, encontramos, inclusive, exemplos de trabalhos que seriam executados da mesma forma tanto por homens como por mulheres. Percebe-se uma visão de que, atualmente, há uma emancipação feminina inexistente no passado, mas que alguns problemas, como a diferença salarial entre homens e mulheres ainda persistem.

Porém, de acordo com os escritos das alunas, a igualdade entre homens e mulheres não se dá de forma completa, já que ambos teriam habilidades que sobressaíam mais de acordo com o gênero. Para as alunas, a mulher pode exercer múltiplas funções, mas não deve abdicar das atividades historicamente dedicadas a elas. Da mesma forma, em alguns trechos, conseguimos 
perceber que os papéis de cuidado com a casa e com os filhos, apesar de poderem ser praticados por homens, seriam executados com mais êxito por uma mulher, visto que, quando um homem o fizesse ele estaria a superar esta habilidade feminina.

\section{A relação entre a educação feminina e o papel social da mulher durante os séculos XVIII e XIX e a vida das alunas}

Todo mundo onde eu moro conhece alguém que já foi preso (...) se eu tivesse tido mais oportunidades talvez eu não estivesse presa (...) se a gente se esforçar a gente consegue chegar aonde quer (..) eu acho que todos esses filósofos são machistas. (Relatos retirados do diário de campo etnográfico)

Ao tratar de pessoas envolvidas com a ciência da época e expor suas relações de parentesco, como por exemplo, as relações de parentesco entre Erasmus Darwin e Charles Darwin, a professora-pesquisadora expôs situações e privilégios sociais necessários para que um indivíduo conseguisse, naquele contexto, pleitear a carreira científica e obter sucesso. Ao mesmo tempo, discutimos a situação social das alunas, e a maioria expôs que seus pais e parentes próximos não concluíram a educação básica e que muitos conhecidos e parentes também já tinham sido presos, o que levou uma das alunas à conclusão de que esta situação se devia à falta de oportunidades dadas ao grupo social a que elas pertenciam.

O termo machismo surgiu novamente e foi citado diversas vezes pelas alunas, assim como a indignação com a visão filosófica dominante sobre o papel da mulher. Elas acharam graça das disciplinas propostas para as mulheres pelo plano de estudos de Erasmus Darwin (DARWIN, 1798), que continha tópicos como vestimentas, modos de falar e castidade. Ao observar algumas pinturas (Figuras 6, 7 e 8), uma delas com uma criança sendo educada por uma mulher (Figura 6), elas sinalizaram novamente a etnia das pessoas retratadas.

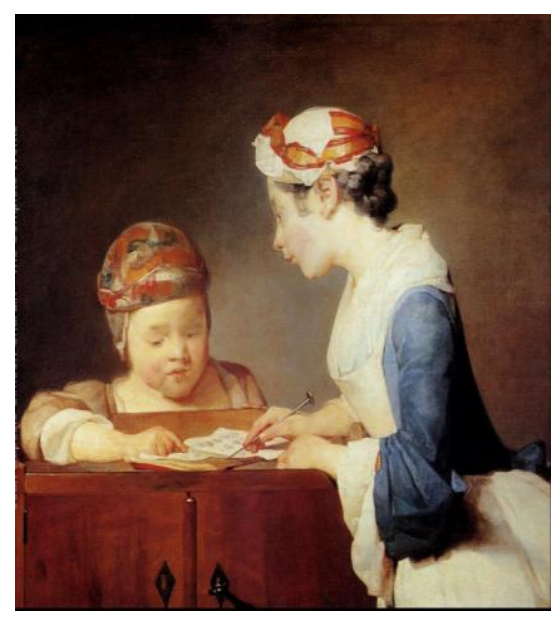

Figura 6 - Pintura The Young Schoolmistress de Jean-Baptiste-Simeon Chardin, 1736. Fonte: Chardin (1736) 


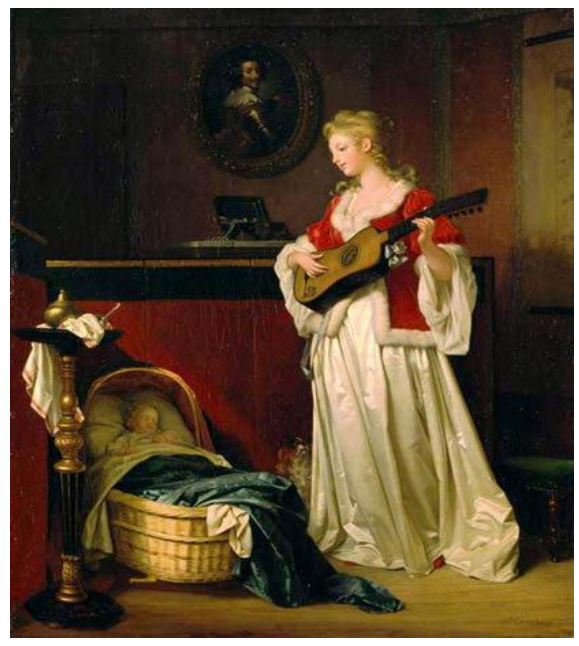

Figura 7 - Pintura Sleep my child da francesa Marguerite Gérard (1761-1837), de 1783. Fonte: Gérard (1783)

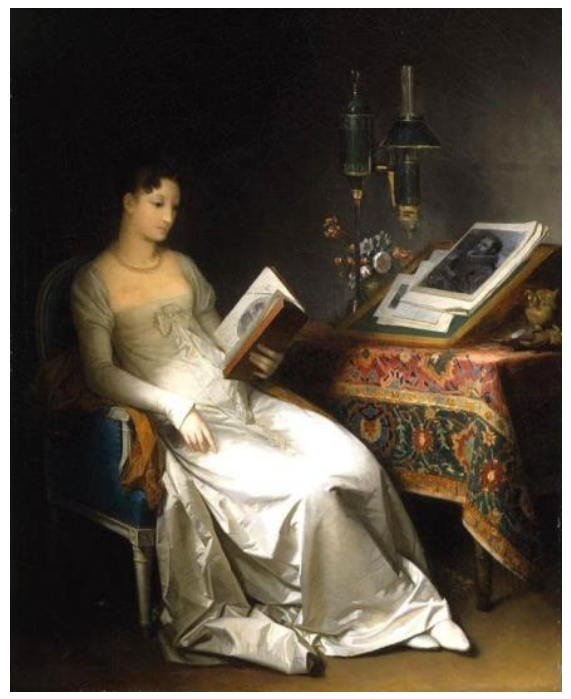

Figura 8 - Pintura Lady reading in a interior da pintora francesa Marguerite Gérard (17611837), de 1795.

Fonte: Gérard (1795).

Durante a conversa com as alunas sobre como ser mulher teria interferido nas escolhas e rumos da vida, elas citaram que o relacionamento conjugal precoce foi decisivo para a situação de encarceramento em que hoje se encontram e que, caso tivessem nascido homens teriam tido ações diferentes. Ao falarmos sobre os estudos e como a maternidade na adolescência as teria afetado, elas atribuíram o abandono da escola à falta de persistência e esforço pessoal, não citando a possibilidade de que algum suporte, governamental ou do companheiro pudesse inverter a situação.

\section{A botânica como ciência: suas especificidades e desafios}

Eu não sei desenhar (...) A flor dela ficou boa porque ela já fez aula de desenho (...) Cannabis sativa é nome científico? (...) Eu lembro que tem mamão macho e mamão 
fêmea (...). por que planta exótica é ruim? (...) no meu poema o pólen vai ser como uma neve que cai de noite. (Relatos retirados do diário de campo etnográfico)

O papel dos naturalistas ao longo dos séculos XVIII e XIX abriu caminho para a discussão de muitos temas relativos à Biologia, como espécies exóticas e nativas, ecossistemas, equilíbrio ecológico, biodiversidade, nomenclatura científica e biologia vegetal. Ao tratar questões específicas da Biologia e da Botânica, as alunas fizeram ligações com conhecimentos anteriores, como foi o caso do nome científico da espécie humana, que fez com que lembrassem do nome científico da maconha. Esse mesmo tema trouxe à tona a candidíase, que é muito comum em mulheres, e outras IST's. A discussão sobre a classificação sexual das plantas, proposto por Linnaeus, fez com que as alunas recordassem plantas, como o "mamão-macho", e discutissem o termo homossexualidade, no reino vegetal e na cultura humana.

Durante duas aulas, foi possível fazer com que as alunas experimentassem uma forma de prática botânica, com a utilização da lupa, uma ferramenta utilizada para a análise das estruturas florais ainda nos dias de hoje. Foram usadas imagens reais de livros escritos por mulheres do século XVIII (Figura 9) e discutidas as formas que usaram para esquematizar as estruturas vegetais; alguns livros utilizavam o sistema de classificação sexual e outros não. A atividade proposta consistia em desenhar flores (Figura 10) que existiam dentro da penitenciária (Malvaviscus arborius e Ipomoea cairica) e fez com que as alunas destacassem as dificuldades envolvidas na ilustração botânica, que passavam tanto pela necessidade de treinamento em desenho, como pela presença de materiais necessários à confecção do desenho, fora ser necessário instrução em Botânica nos moldes científicos. Isso as levou à conclusão de que, mesmo com a possibilidade de participação feminina na tarefa de ilustração botânica, essa não era uma chance passível a todas as mulheres, visto que para participarem, as mulheres teriam que ter acesso a condições educacionais específicas e privilégios sociais.

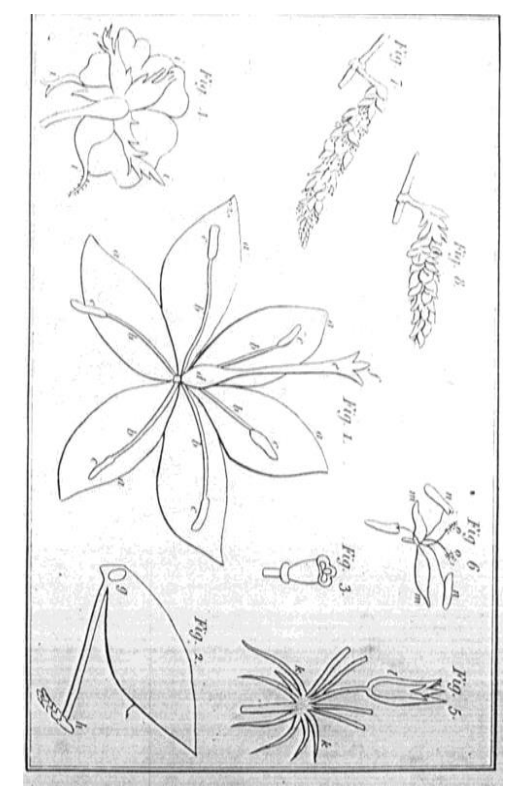

Figura 9 - Página do livro Botanical Dialogues escrito por Maria Jacson, em 1797 demonstrando desenhos esquemáticos sobre as estruturas florais.

Fonte: Jacson (1797) 


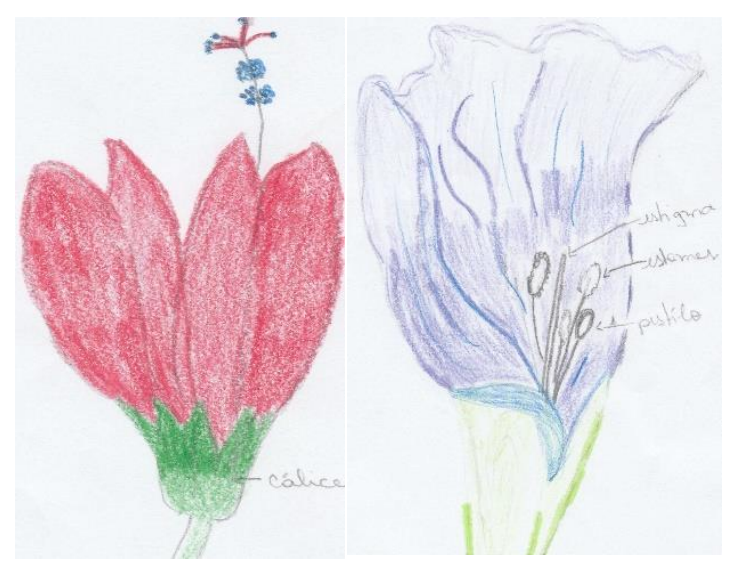

Figura 10 -Ilustrações botânicas produzidas pelas alunas. À esquerda a partir de espécime de Malvaviscus arborius e à direita de espécie de Ipomoea cairica.

Fonte: Dados da pesquisa.

Ao explanar sobre as práticas botânicas comumente realizadas por mulheres, discutimos a consonância desta prática com a permanência da mulher nas esferas privadas e do lar. A pintura da mulher, com os filhos no jardim (Figura 11), deu uma demonstração do cotidiano feminino burguês no século XVIII e promoveu falas nas quais as alunas indicaram a etnia dos indivíduos retratados e a relação entre mãe e filha na imagem.

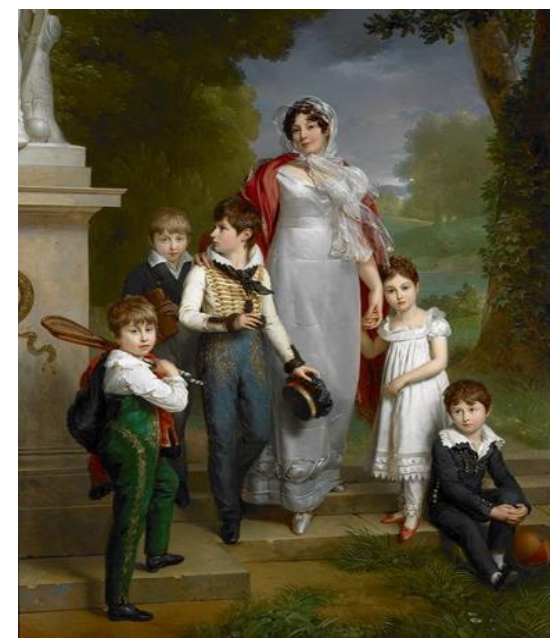

Figura 11 - Pintura Portrait of Louise-Antoinet-Scholastique Guéhéneuc, Madame la Maréchale Lannes, Duchesse de Montebello, with her Children", de Baron Francois Gérard (1770-1837), de 1814. A mulher, retratada com seus 5 filhos ao ar livre, era viúva de um dos generais de Napoleão Bonaparte (1769-1821).

Fonte: Gérard (1814)

Trabalhamos também as características florais, dando ênfase às características específicas de cada gênero a partir de trechos dos poemas botânicos de Erasmus Darwin (DARWIN, 1798b):

"Thy love, CALLITRICHE, two virgins share, Smit with thy starry eye and radiant hair” (DARWIN, 1798b, p. 7).

"The freckled IRIS owns a fiercer flame, And three unjealous husbands wed the dame" (DARWIN, 1798b, p. 10). 
"Weak with nice sense, the chaste MIMOSA stands, From each rude touch withdraws her timid hands" (DARWIN, 1798b, p.21).

Como as alunas não eram fluentes em inglês, a professora pesquisadora lia o trecho no idioma e imediatamente realizava uma livre tradução do mesmo para a turma.

Segundo as alunas, após ouvirem os poemas, essa forma de falar sobre as espécies proposta por Erasmus Darwin seria interessante e facilitaria a assimilação das características da planta. Porém, o desconhecimento prévio dos gêneros botânicos abordados no poema dificultou a interpretação desses pelas alunas.

Em seguida foi proposto que as alunas produzissem seus próprios poemas botânicos, a partir de duas espécies coletadas no espaço prisional (Malvaviscus arborius e Ipomoea cairica). Nos poemas das alunas, assim como no poema de Erasmus Darwin, observamos um imaginário antropomórfico, com ênfase na coloração da flor e na disposição e número das estruturas reprodutoras, bem como em características do instante observado, como a presença de pólen e néctar e a perenidade da corola:

Havia várias mulheres de cabelos vermelhos e pele aveludada que estavam chamando a atenção dos diversos rapazes que ali se encontravam, elas eram doces como um cálice de água cristalina. (Poema realizado pelas alunas a partir da observação de um espécime de Malvaviscus arborius).

Havia naquele jardim muitas cores roxas e lilás. Naquela multidão de cores estavam 5 rapazes venerando uma linda moça que se encontrava ali sozinha e desprotegida com sua beleza frágil a mercê do tempo em uma noite muito fria que ventava bastante e trazia a neve que caía insistentemente. (Poema realizado pelas alunas a partir da observação de um espécime de Ipomoea cairica)

\section{Considerações finais}

A pesquisa histórica, a partir de um viés da HCC, mostrou-se uma ferramenta importante para promover em sala de aula um espaço de discussões relativas a gênero. O caminho escolhido, ou seja, o estudo das práticas científicas como constituintes de um contexto cultural complexo, permitiu problematizar as relações de poder econômico e político, as representações sociais e tantas outras questões presentes na sociedade da época, como é o caso do papel social da mulher. Portanto, o olhar cultural para a história da ciência em uma abordagem da História Cultural da Ciência proporcionou a associação entre as práticas científicas feitas por homens e mulheres durante os séculos XVIII e XIX, como sendo necessariamente parte integrante desse contexto.

Como aponta o estudo histórico, as mulheres tinham participação ativa no meio científico do contexto histórico estudado. Porém, os limites para a sua atuação, assim como as atividades que exerciam e seu grau de prestígio estavam diretamente ligados à visão filosófica da natureza da mulher e do seu papel na sociedade iluminista. Por isso, consideramos necessário o debate sobre as práticas efetivamente realizadas pelas mulheres na botânica nos séculos XVIII e XIX, uma vez que a promoção delas como política de Estado, assim como a permissividade ou não dessas práticas, estava relacionada ao que era desejável à educação feminina da época. Importante destacar que esse contexto está relacionado às formas com as quais a ciência foi construída e hoje se sustenta.

A abordagem histórica adotada possibilitou não apenas visibilizar as mulheres como produtoras de conhecimento científico durante os séculos XVIII e XIX, mas, também, promover indagações de quem eram essas mulheres: sua cor, sua classe social, sua localização 
geográfica e seus privilégios. A partir dessas discussões, foi possível naquelas aulas de ciências problematizar a não inserção no ambiente científico de tantas outras mulheres com perfis distintos a esse.

Essa problematização mostrou-se importante, principalmente quando pensamos no público com o qual realizamos a pesquisa. Esse público era composto de mulheres, momentaneamente privadas de liberdade, que trazem histórias de vida marcadas pela violência e negação de direitos e que, por características não determinadas por elas, já nasceram com possibilidades restritas de futuro.

Os resultados obtidos na narrativa etnográfica trouxeram enunciados importantes das alunas quanto à percepção delas enquanto mulheres, mães, negras, periféricas e privadas de liberdade e promoveram a identificação do machismo sofrido por elas em diversos momentos de suas histórias de vida. Conjuntamente a esses temas foram tratados os conteúdos de biologia propriamente ditos, que foram ressignificados e reencaminhados através da percepção de mundo delas e de suas experiências enquanto mulheres.

Todas as alunas participantes explicitaram ser urgente e necessária a igualdade de oportunidades para homens e mulheres, mas as percepções sobre os papéis sociais e características dos diferentes gêneros pareceu controversa. Porém, esse é um tema caro e complexo e muito ainda temos a avançar nessas construções e discussões, até porque essas não são questões dadas, nem mesmo no campo da ciência. Há que, cada vez mais, se trazer para a sala de aula temas que problematizem a baixa representatividade de certos atores sociais na ciência, como as mulheres.

\section{Referências}

BARCINSKI, M. Mulheres no tráfico de drogas: a criminalidade como estratégia de saída da invisibilidade social feminina. Contextos clínicos, v. 5, n. 1, p. 52-61, 2012.

BRASIL. Comitê Nacional de Educação em Direitos Humanos. Plano Nacional de Educação em Direitos Humanos. Brasília: Secretaria Especial dos Direitos Humanos, Ministério da Educação, 2007.

BRASIL. Conselho Nacional de Educação. Diretrizes Curriculares Nacionais para a Educação Ambiental. Resolução $\mathrm{CNE} / \mathrm{CP} \mathrm{n}^{\circ}$ 2, de 15 de junho de 2012. Brasília, Diário Oficial da República Federativa do Brasil, Seção 1, p. 70, 18 de junho de 2012.

BRASIL. Conselho Nacional de Educação. Diretrizes Nacionais para a Educação em Direitos Humanos. Resolução CNE/CP nº 1, de 30 de maio de 2012. Brasília, Diário Oficial d] República Federativa do Brasil, Seção 1, p. 48, 31 de maio de 2012.

BRASIL. Conselho Nacional de Educação. Diretrizes Curriculares Nacionais Gerais para a Educação Básica. Resolução CNE/CEB no 4, de 13 de julho de 2010. Brasília, Diário Oficial da República Federativa do Brasil, 14 de julho de 2010, Seção 1, p. 824, 2010.

BRASIL. Conselho Nacional de Educação. Diretrizes Curriculares Nacionais para a Educação das Relações Étnico-Raciais e para o Ensino de História e Cultura AfroBrasileira e Africana. Resolução CNE/CP no 1, de 17 de junho de 2004. Brasília, Diário Oficial da República Federativa do Brasil, 22 de junho de 2004, Seção 1, p. 11, 2004. 
BRASIL. Lei de Diretrizes e Bases da Educação: Lei no 9.394/96 de 24 de dezembro de 1996. Estabelece as diretrizes e bases da educação nacional. Brasília, 1996.

BRASIL. Lei Maria da Penha: Lei ${ }^{\circ} 11.340 / 2006$ de 7 de agosto de 2006 . Cria mecanismos para coibir a violência doméstica e familiar contra a mulher. Brasília, 2006.

BRASIL. Levantamento Nacional de Informações Penitenciárias (INFOPEN). Atualização junho de 2016. Brasília: Ministério da Justiça e Segurança Pública. Departamento Penitenciário Nacional, 2017.

BRASIL. Plano Nacional de Educação: Lei 13.005/14 de 25 de junho de 2014. Aprova o Plano Nacional de Educação - PNE e dá outras providências. Brasília, 2014.

BLEICHMAR, D. The Geography of Observation: Distance and Visibility in EighteenthCentury Botanical Travel. In: DASTON, L.; LUNBECK, E. Histories of Scientific Observation. The University of Chicago Press, p. 373-395, 2011.

BURKE, P. A República das Letras Europeia, 1500-2000. Estudos Avançados, v. 25, n.72, p 277-288, 2011.

CAMEL, T.; MOURA, C.; GUERRA, A. Revolução Química e Historiografia: uma releitura a partir da História Cultural da Ciência para o Ensino de Química. Educacíon Química, v. 30, p. 136, 2019.

CHARDIN, J. B. S. Allegory of Science. 1765. Pintura. Disponível em: <https://www.1st-artgallery.com/Jean-Baptiste-Simeon-Chardin/Allegory-Of-Science.html >. Acesso em: 10 jun. 2021.

CHARDIN, J. B. S. The Young Schoolmistress. 1736. Pintura. Disponível em: $<$ https://www.1st-art-gallery.com/Jean-Baptiste-Simeon-Chardin/The-Young-SchoolmistressC.-1736.html >. Acesso em: 10 jun. 2021.

DARWIN, E. A plan for the conduct of female education, in boarding schools, private families, and public seminaries. Philadelphia: Printed by John Ormrod, n. 41, Chesnut-Street, 1798a. Disponível em: <https://archive.org/details/planforconductof00darwrich> Acesso em: 10 jun. 2021.

DARWIN, E. The Botanic Garden: a poem, in two parts. Part I. Containing the economy of vegetation. Part II. The loves of the plants: with philosophical notes. New York: Printed by J. Swords, printers to the faculty of physic of Columbia College, n. 99, Pearl Street, 1798b. Disponível em: <https://archive.org/details/thebotanicgarden00darwrich> Acesso em: 10 jun. 2021.

DASTON, L. History of Science Without Structure. In: RICHARDS, R. J.; DASTON, L. Kuhn's Structure of Science Revolutions at fifty. Reflections on a Science Classic. University of Chicago Press, p. 115- 132, 2016.

ECKSTEIN, J. John Freeth and his Circle. 1792. Pintura. Disponível em: $<$ http://www.bmagprints.org.uk/image/407344/johannes-eckstein-john-freeth-and-his-circleor-birmingham-men-of-the-last-century>. Acesso em: 5 jun. 2021. 
GASPAR, A. M. A Representação das Mulheres no Discurso dos Filósofos: Hume, Rousseau, Kant e Condorcet. Uapê: SEAF, Rio de Janeiro, 2009.

GAVROGLU, K. O passado das Ciências como História. Porto Editora, 2007.

GEORGE, S. Cultivating the Botanical Woman: Rousseau, Wakefield and the Instruction of Ladies in Botany. ZpH Jg., v. 12, n. 1, p. 3-11, 2006.

GEORGE, S. Carl Linnaeus, Erasmus Darwin and Anna Seward: Botanical Poetry and Female Education. Science \& Education, n. 23, p. 673-694, 2014.

GÉRARD, B. F. Portrait of Louise-Antoinet-Scholastique Gué héneuc, Madame la Maréchale Lannes, Duchesse de Montebello, with her children. 1814. Pintura. Disponível em: <https://artsandculture.google.com/asset/portrait-of-louise-antoinette-scholastiquegu\%C3\%A9h\%C3\%A9neuc-madame-la-mar\%C3\%A9chale-lannes-duchesse-de-montebellowith-her-children/EwFZgTIu7_f12g>. Acesso em: 09 jun. 2021.

GÉRARD, M. Lady reading in a interior. 1795. Pintura. Disponível em: <https://commons.wikimedia.org/wiki/File:Marguerite_G\%C3\%A9rard_-

_Lady_Reading_in_an_Interior_-_WGA8609.jpg > Acesso em: 21 jun. 2021.

GÉRARD, M. Sleep my child. 1783. Pintura. Disponível em: <https://es.wikipedia.org/wiki/Marguerite_G\%C3\%A9rard\#/media/File:Marguerite_G\%C3\% A9rard_-_Sleep_my_child.jpg>. Acesso em: 18 jun. 2021.

GIANQUITTO, T. "Good observers of nature": American women and the scientific study of the natural world, 1820-1885. Athens: University of Georgia Press, 2007.

GOULD, J. A century of birds from the Himalaya Mountains. London, 1831. Disponível em: <https://archive.org/details/centurybirdsfro00Goul> Acesso em: 05 jun. 2021.

GRONIM, S. S. What Jane Knew: A Woman Botanist in the Eighteenth Century. Journal of Women`s History, v. 19, n. 3, p. 33-59, 2007.

JACSON, M. Botanical Dialogues: Between Hortensia and her Four Children, Charles, Harriet, Juliette and Henry. London, printed for J. Johson, in St. Paul's Church-Yard, 1797. Disponível em: <https://archive.org/details/b28762514>. Acesso em: 04 dez. 2021.

JAGER, I. Discutindo gênero com mulheres privadas de liberdade: um olhar da história cultural da ciência para o desenvolvimento da botânica nos séculos XVIII e XIX. 2018. Dissertação (Mestrado em Ciência, Tecnologia e Educação) - Centro Federal de Educação Tecnológica Celso Suckow da Fonseca, 2018.

JAGER, I. T.; MELLO, A. L.; FERREIRA, M.; GUIMARAES, R. Quem são elas e o que querem? Perfil de mulheres privadas de liberdade alunas da Educação de Jovens e Adultos de um presídio carioca. Revista Educação e Cultura Contemporânea, v. 18, n. 53, p. 182-203, 2021. 
JARDIM, W. T.; GUERRA, A. República das Letras, Academias e Sociedades Científicas no Século VIII: A Garrafa de Leiden e a Ciência no Ensino. Caderno Brasileiro de Ensino de Física, v. 34, p. 774-797, 2017.

LOIZOS, P. Vídeo, filme e fotografias como documentos de pesquisa. In: BAUER, M., W; GASKELL, G. Pesquisa qualitativa com texto, imagem e som: um manual prático. Rio de Janeiro: Vozes, p. 137- 155, 2015.

LOUDON, J. W. Ladies' Flower-Garden of Ornamental Greenhouse Plants. London: William Smith, 1841. Disponível em: <https://archive.org/details/gardladiesflower00loudrich>. Acesso em: 30 jun. 2021.

MATTOS, C. L. G. A abordagem etnográfica na investigação científica. In: MATTOS, C. L. G.; CASTRO, P. A. (Orgs.) Etnografia e educação: conceitos e usos. Campina Grande: EDUEPB, p. 49-83, 2011.

MINZON, C.; DANNER, G. K.; BARRETO, D. J. Sistema Prisional: Conhecendo as vivências da mulher inserida neste contexto. Akrópolis, Umuarama, v. 18, n. 1, p. 71-81, 2010.

MOURA, C. B.; GUERRA, A. História Cultural da Ciência: um caminho possível para a discussão sobre as práticas científicas no Ensino de Ciências? Revista Brasileira de Pesquisa em Educação em Ciências, v. 16, n. 3, p. 725-748, 2016.

MOURA, M. J.; FROTA, M. H. P. Dilacerando os fios, tricotando às avessas, construindo a trama: mulher, tráfico de drogas e prisão. Revista Público e o Privado, n. 8, 2006.

MUZZIN, L. Education and Science. In: RESTIVO, S. Science, Technology, and Society. An Encyclopedia. Oxford Press, p. 98-105, 2005.

OLIVEIRA, A. Algumas pistas (e armadilhas) na utilização da Etnografia na educação. Educação em foco, ano16, n. 22, p. 163-183, 2013.

OLIVEIRA, R. D. V. L.; QUEIROZ, G. R. P. C. O cotidiano, o contextualizado e a Educação em Direitos Humanos: a escolha de um caminho para uma educação cidadã cosmopolita. In: OLIVEIRA, R. D. V. L.; QUEIROZ, G. R. P. C. (Org.). Tecendo Diálogos sobre Direitos Humanos na Educação em Ciências, p. 61- 98, 2016.

ORTEGA, C. G. Instrucción sobre el modo más seguro y económico de transportar plantas vivas por mar y tierra á los países más distantes: ilustrada con láminas. Añádese el metodo de desecar las plantas para formar herbarios; dispuesta por orden del rey. Madrid: D. Joachin Ibarra, 1779. Disponível em: <http://bibdigital.rjb.csic.es/ing/Libro.php?Libro=3732> . Acesso em: 06 maio 2021.

PAGE, J. W; SMITH, E. L. Woman, literature, and the domesticated landscape: Englad's disciples of Flora, 1780-1870. Cambridge University Press, 2011.

PIMENTEL, J. La Revolucíon Científica. In: Artola, M. (dir.) Historia de Europa: Tomo II. Madrid: Espasa Calpe, p. 163-238, 2007. 
PIMENTEL, J. ¿Qué es la historia cultural de la ciencia? Arbor, v. 186, n. 743, p. 417-424, 2010.

REYNOLDS, J. Joseph Banks. 1773. Pintura. Disponível em: <https://en.wikipedia.org/wiki/Joseph_Banks\#/media/File:Joseph_Banks_1773_Reynolds.jpg >. Acesso em: 29 maio 2021.

SHEFFIELD, S. L. Women and Science: Social Impact and Interaction. Rutgers University Press, 2006.

SHTEIR, A. Botanical Dialogues: Maria Jacson and Women's Popular Science Writing in England. Eighteenth-Century Studies, v. 23, n. 3, p. 301-317, 1990.

SHTEIR, A. "She comes! - The Goddess!": Narrating Nature in Erasmus Darwin's The Botanic Garden. In: LEHLEITER, C. Fact and fiction: literary and scientific cultures in Germany and Britain. University of Toronto Press, 2016.

SIGRIST, R.; WIDMER, E. D. Training links and transmission of Knowledge in 18 th century botany: A social network analysis. Revista hispana para el análises de redes sociales, vl. 21, n. 17, 2011. 